\title{
Internal associations and dynamic expression of c-kit and nanog genes in ventricular remodelling induced by adriamycin
}

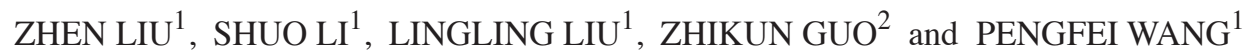 \\ ${ }^{1}$ Department of Cardiology, Xinxiang Central Hospital; ${ }^{2}$ Key Laboratory for Medical Tissue Regeneration, \\ Xinxiang Medical University, Xinxiang, Henan 453003, P.R. China
}

Received March 5, 2015; Accepted March 15, 2016

DOI: $10.3892 /$ etm.2016.3522

\begin{abstract}
The present study aimed to investigate the dynamic expression of the c-kit and nanog genes in rats with left ventricular remodelling induced by adriamycin (ADR), and explore its internal association and mechanism of action. Sprague-Dawley male rats were randomly divided into a normal control group and a heart failure model group. Heart failure was induced by a single intraperitoneal injection of ADR ( $4 \mathrm{mg} / \mathrm{kg})$ weekly for six weeks. The normal control group was given the same amount of saline. At the eighth week, rat cardiac function was examined to demonstrate the formation of heart failure. The rat hearts were harvested frozen and sectioned, and the expression levels of the nanog and c-kit genes in the myocardial tissue samples were detected using immunohistochemistry, immunofluorescence and reverse transcription-polymerase chain reaction (RT-PCR). Hematoxylin and eosin staining demonstrated various pathological changes in the myocardial cells in the heart failure model group, whereas myocardial infarction was not observed in the normal control group. Immunohistochemistry and immunofluorescence demonstrated that nanog-positive cells were predominantly expressed in the vascular endothelium, with a few myocardial cells and stem cells in normal myocardium. The expression levels of c-kit and nanog in the myocardium of the rats with heart failure decreased significantly. c-kit-positive cells clustered together in the epicardium and its vicinity, and c-kit expression significantly decreased in the myocardium of rats with heart failure, as compared with normal rats. In both groups, some cells co-expressed both the c-kit and nanog genes. The RT-PCR results demonstrated that the expression levels of the two genes in the heart failure model group were significantly lower compared with those in the normal control group $(\mathrm{P}<0.05)$. In conclusion, the c-kit- and nanog-positive stem cells decreased in the myocardium of the rats with left ventricular remodelling induced by ADR. Their abnormal expression was significantly
\end{abstract}

Correspondence to: Professor Lingling Liu, Department of Cardiology, Xinxiang Central Hospital, 56 Jinsui Road, Xinxiang, Henan 453003, P.R. China

E-mail: linglingliucn@126.com

Key words: cardiac stem cells, c-kit, nanog, ventricular remodelling correlated with left ventricular remodelling, thereby indicating an internal association (influences of two indexes in the experimental group and control group) between them.

\section{Introduction}

Acute myocardial infarction (AMI) is a costly cardiovascular disease with a high mortality rate (1). The average hospitalization costs are high (2). Furthermore, the morbidity, disability and mortality of heart failure following myocardial infarction severely affects the quality of life of the patient and community health care resources. Therefore, measures that can effectively hinder the damage associated with heart failure are important. AMI is the predominant cause of myocardial infarction, and left ventricular remodelling (LVM) occurs at a later stage (3). LVM refers to the pathological changes in the immune activation state of the body caused by large amounts of cytokines secreted by myocardial cells, under the influence of injury, ventricular wall stress, oxidative stress and partial activation of the neuroendocrine system, which induces myocardial collagen deposition and changes in collagen type and collagen degradation (4). Recent studies on LVM reported the presence of stem cells in the myocardium, which have the ability to differentiate into various cells $(5,6)$. A small number of stem cells are able to express c-kit and nanog surface markers. These cardiac stem cells can differentiate are able to cardiomyocytes both in vitro and in vivo (7), and cardiac stem cells have been suggested to provide inherent damage repair and reserve ability in myocardial cells. However, analyses on the expression of cardiac stem cells, as well as the regenerative capacity of the myocardium and cardiac-associated factors in ventricular remodelling are limited $(8,9)$. Furthermore, whether the number of myocardial stem cells increase or decrease subsequent to heart failure, and whether myocardial regeneration is enhanced or diminished remains to be elucidated. The present study established a theoretical basis for potential myocardial regeneration and gene therapy following heart failure by examining the pathological changes and dynamic expression of c-kit- and nanog-positive stem cells.

\section{Materials and methods}

Animal groups. A total of 40 Sprague-Dawley male rats, weighing 230-250 $\pm 2.5 \mathrm{~g}$, were provided by the Animal Centre 
of the Xinxiang Medial University (Xinxiang, China). The rats were randomly divided into a normal control $(\mathrm{CON})$ group $(n=15)$ and a heart failure model group $(n=25)$. The present study was performed in strict accordance with the recommendations in the eighth edition 2010 Guide for the Care and Use of Laboratory Animals of the National Institutes of Health $(10,11)$. The animal use protocol was reviewed and approved by the Institutional Animal Care and Use Committee of the Xinxiang Central Hospital (Xinxiang, China).

Heart failure model. Rats in the heart failure group were intraperitoneally administered with $4 \mathrm{mg} / \mathrm{kg}$ adriamycin (ADR; Sangon Biotech Co., Ltd., Shanghai, China) weekly for six weeks. Rats in the CON group were given the equivalent amount of saline. After eight weeks, both groups were subjected to echocardiography using an ACUSON SC2000 (Siemens AG, Munich, Germany), with left ventricular ejection fraction (LVEF) $<45 \%$ being the criterion of heart failure (12).

Material collection. The rats identified to have successfully developed heart failure following treatment with ADR were anesthetized using $10 \%$ chloral hydrate $(0.3 \mathrm{ml} / 100 \mathrm{~g}$ [lethal dose); Sangon Biotech Co.,Ltd.] and then immediately subjected to thoracotomy. The rat hearts were rapidly eviscerated, and residual blood was removed using ice-cold phosphate-buffered saline (PBS) buffer. The large blood vessels and surrounding tissues were removed with scissors. Approximately one half of the hearts were packed in cryogenic vials (Dingguo Changsheng Biotechnology Co., Ltd., Beijing, China), rapidly frozen with liquid nitrogen and transferred to a $-80^{\circ} \mathrm{C}$ refrigerator. The remaining half was placed in $4 \%$ paraformaldehyde (Sangon Biotech Co., Ltd.) for fixation for $12 \mathrm{~h}$, followed by gradient dehydration with 20 and 30\% sucrose (myocardial cells can sink to the bottom) purchased from Sangon Biotech Co., Ltd. Tissue sections (thickness, $10 \mu \mathrm{m}$ using a microtome from Dingguo Changsheng Biotechnology Co., Ltd.) were frozen using a cryostat frozen section machine (CM1900; Leica Microsystems GmbH, Wetzlar, Germany), and used for masson staining (cat no. HT15-1KT; Sigma-Aldrich, St. Louis, $\mathrm{MO}, \mathrm{USA}$ ) at $37^{\circ} \mathrm{C}$ for $30 \mathrm{~min}$, immunohistochemistry and immunofluorescence.

Immunohistochemistry. The frozen tissue sections were heated in an oven for $30 \mathrm{~min}$ at $37^{\circ} \mathrm{C}$, washed three times with PBS for 5 min each time, maintained for $15 \mathrm{~min}$ in $0.3 \%$ Triton-X-100 PBS liquid and soaked in a mixture of $30 \%$ hydrogen peroxide and methanol (1:50 ratios) all Sangon Biotech Co., Ltd) for 30 min to block endogenous peroxidase activity. The tissue sections were treated at room temperature for $20 \mathrm{~min}$ with goat serum (Sijiqing, Hangzhou, China) containing rabbit anti-rat nanog polyclonal antibody (1:200; cat no. sc-376915; Santa Cruz Biotechnology, Inc., Dallas, TX, USA) and mouse anti-rat c-kit monoclonal antibody (1:100; cat no. sc-17806; Santa Cruz Biotechnology, Inc.). The serum was subsequently centrifuged at $5,000 \mathrm{x} \mathrm{g}$ for $3 \mathrm{~min}$ at $37^{\circ} \mathrm{C}$. The tissue sections were incubated overnight at $4^{\circ} \mathrm{C}$ in a wet box (Dingguo Changsheng Biotechnology Co., Ltd.) and then rewarmed for $30 \mathrm{~min}$ at room temperature. The tissue sections were treated with reagent $\mathrm{B}$, incubated for $15 \mathrm{~min}$ at $37^{\circ} \mathrm{C}$, washed three times with PBS for 5 min each time, treated with reagent $\mathrm{C}$ (both reagents purchased from Dingguo Changsheng Biotechnology Co., Ltd.), incubated for $15 \mathrm{~min}$ at $37^{\circ} \mathrm{C}$ and washed three times with PBS for 5 min each time. The sections were then treated with diaminobenzidine (Sangon Biotech Co., Ltd.) at room temperature, thoroughly rinsed with distilled water and counterstained in hematoxylin (Sangon Biotech Co., Ltd.). Images were captured using an Olympus AX80 (Olympus Corporation, Tokyo, Japan) following dehydration by gradient elution using ethanol, and neutral gum mounting (Sangon Biotech Co., Ltd.). The CON group was performed by a dilution of primary antibody instead of primary antibody during immunohistochemistry.

Immunofluorescence. Frozen tissue sections were heated in an oven for $30 \mathrm{~min}$ at $37^{\circ} \mathrm{C}$. Following three washes with PBS for $5 \mathrm{~min}$ each time, the sections were maintained for $15 \mathrm{~min}$ in $0.3 \%$ Triton-X-100 PBS liquid, treated at room temperature for 20 min with goat serum containing the rabbit anti-rat nanog polyclonal antibody (1:200) and the mouse anti-rat c-kit monoclonal antibody $(1: 100)$, and incubated overnight at $4^{\circ} \mathrm{C}$ in a wet box. The tissue sections were subsequently rewarmed for $20 \mathrm{~min}$ at room temperature in buffer (Sangon Biotech Co., Ltd.) containing cyanine 3-labelled goat anti-rabbit (1:200; cat no. A0516; Beyotime Institute of Biotechnology, Haimen, China) and fluorescein isothiocyanate-labelled goat anti-mouse (1:100; cat no. P0196; Beyotime Institute of Biotechnology, Shanghai, China), and incubated for $1 \mathrm{~h}$ at $37^{\circ} \mathrm{C}$. The nuclei were counterstained in DAPI (Sangon Biotech Co., Ltd.) for $5 \mathrm{~min}$. The tissue sections were then mounted with antifade mounting medium (Dingguo Changsheng Biotechnology Co., Ltd.), and observed under a fluorescence microscope (Olympus AX80; Olympus Corporation). The CON group was performed by a dilution of primary antibody instead of primary antibody during immunohistochemistry.

Reverse transcription-polymerase chain reaction. Refrigerated myocardial tissue samples $(200 \mathrm{mg})$ were obtained from the same site of heart tissues cut in both groups and then homogenized (LM12-XSB-88; Xihuayi, Beijing, China) with liquid nitrogen. This process was conducted in strict accordance with the manufacturer's protocol in Reverse Transcription kit (cat no. RR036A; Takara Biotechnology Co., Ltd., Dalian, China). Thermocycling conditions included preliminary denaturation at $95^{\circ} \mathrm{C}$ for $2 \mathrm{~min}, 35$ cycles each involving denaturation at $95^{\circ} \mathrm{C}$ for $30 \mathrm{sec}$, annealing at $60^{\circ} \mathrm{C}$ for $30 \mathrm{sec}$, extension at $72^{\circ} \mathrm{C}$ for $3 \mathrm{~min}$. Gel electrophoresis (Tocan, Shanghai, China). Total RNA Extraction kit (Takara Biotechnology Co., Ltd.) was used for RNA extraction (50 $\mu \mathrm{g}$ total RNA was extracted). Target gene and reference gene primers (Sangon Biotech Co., Ltd.) were as follows: c-kit forward, 5'-CTAGCCAGA GACATCAGGA-3', and reverse, 5'-CCATAGGACCAGACA TCAC-3'; nanog forward, 5'-AGAAGATGCGGACTGTGT TC-3', and reverse, 5'-GCTCAGGTTCAGAATGGTAGA-3'; and GAPDH forward, 5'-ATGACTCTACCCACGGCAAG-3', and reverse, 5'-TACTCAGCACCAGCATCACC-3'. The results were observed and analyzed using a Tocan 820 gel imaging system (Tocan), which was based on the integrated absorbance value. c-kit/GAPDH and nanog/GAPDH refer to the relative expression levels of c-kit and nanog mRNA, respectively. The results were based on the integrated absorbance value, and the $2^{-\Delta \Delta c q}$ method was used for quantification of the results (13). 
Table I. Echocardiographic indices of cardiac function of the rats in both the ADR and CON groups at the end of the eighth week of treatment with ADR (results are expressed as means \pm standard deviation).

\begin{tabular}{llcll}
\hline Group & LVDD $(\mathrm{mm})$ & LVSD $(\mathrm{mm})$ & LVEF $(\%)$ & LVFS (\%) \\
\hline CON $(\mathrm{n}=15)$ & $3.972 \pm 1.463$ & $2.102 \pm 1.421$ & $70.94 \pm 1.126$ & $34.94 \pm 1.122$ \\
ADR $(\mathrm{n}=30)$ & $6.726 \pm 0.523^{\mathrm{a}}$ & $5.73 \pm 0.610^{\mathrm{a}}$ & $34.64 \pm 9.105^{\mathrm{a}}$ & $14.76 \pm 3.595^{\mathrm{a}}$ \\
\hline
\end{tabular}

${ }^{a} \mathrm{P}<0.05$, vs. the control group. CON, control; ADR, adriamycin; LVDD, left ventricular diastolic diameter; LVSD, left ventricular systolic diameter; LVEF, left ventricular ejection fraction; LVFS, left ventricular fractional shortening.
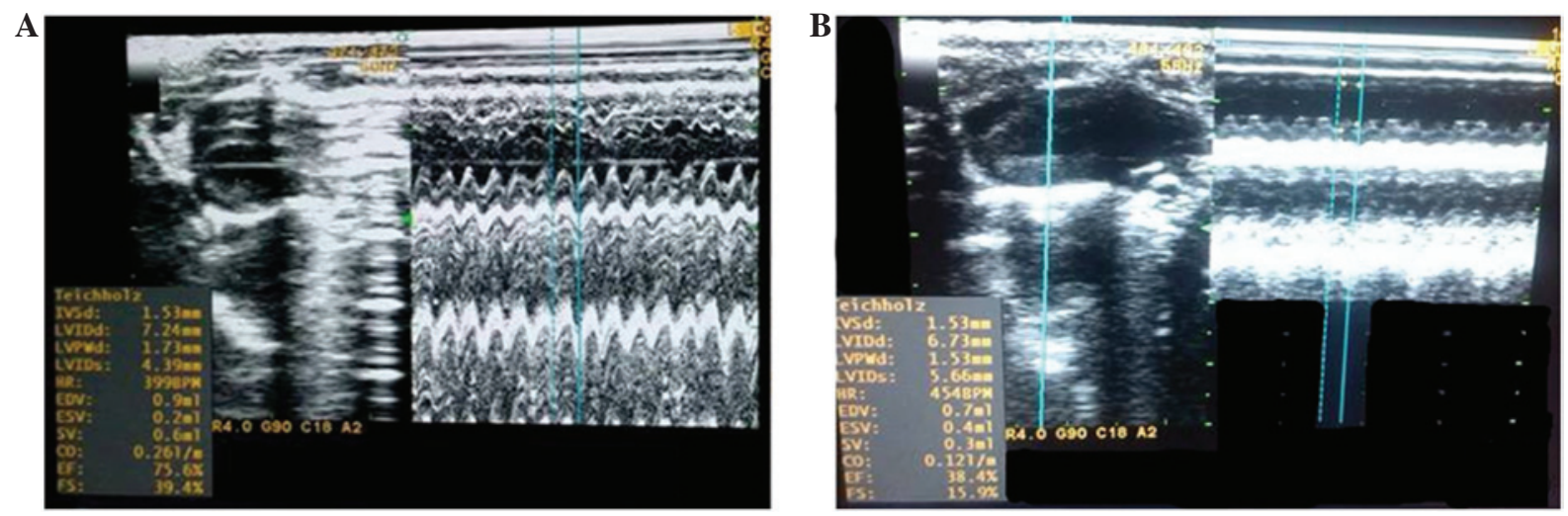

Figure 1. M-type ultrasound of rat hearts from the normal control group and the heart failure model group. (A) Left ventricular ejection fraction of the normal control group (75.6\%). (B) Left ventricular ejection fraction of the heart failure model group (38.4\%).
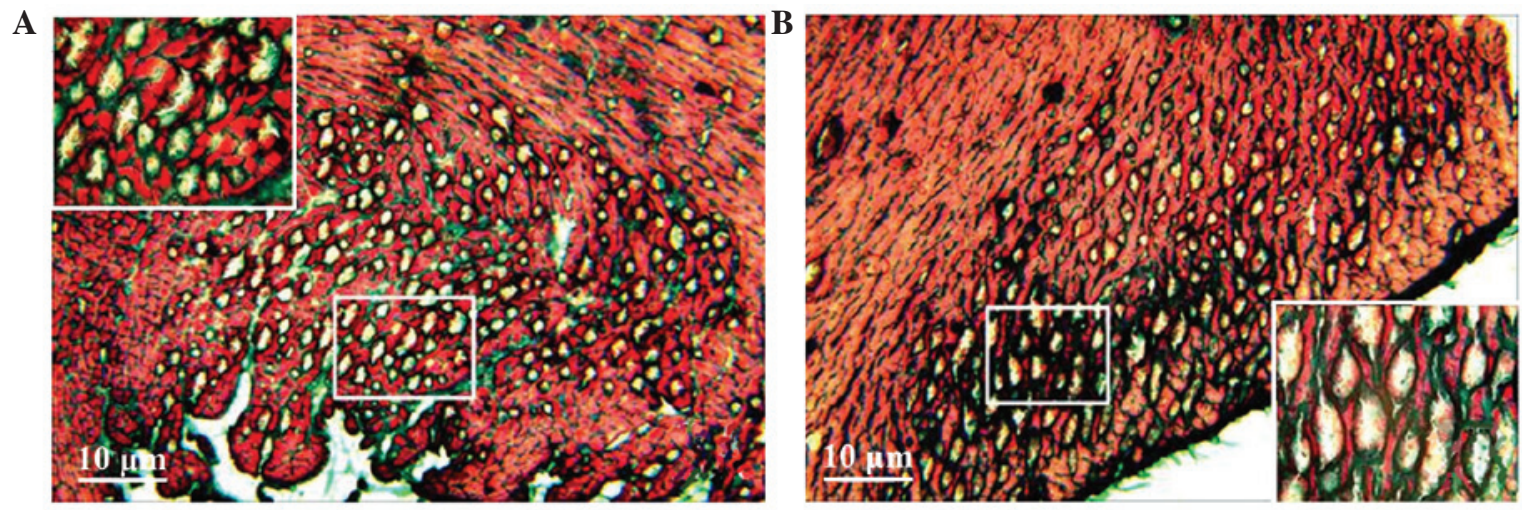

Figure 2. Pathological changes in the myocardial tissue samples of rats with heart failure as shown by Masson staining. (A) Subendocardial myocardium and (B) subepicardial myocardium.

Statistical analysis. The data were expressed as the mean \pm standard deviation. All data analyses were carried out using SPSS version 17.0 (SPSS, Inc., Chicago, IL, USA). Student's paired t-test was used to determine the statistical differences in both groups. $\mathrm{P}<0.05$ was considered to indicate a statistically significant result.

\section{Results}

Changes in cardiac function in rats with heart failure. At the end of the eighth week, the rats in both the ADR and CON groups were subjected to echocardiography. The results demonstrated that cardiac function in the ADR group significantly decreased. Compared with the CON group, left ventricular diastolic diameter and left ventricular systolic diameter were significantly higher $(\mathrm{P}<0.05)$, whereas LVEF and left ventricular fractional shortening were significantly lower $(\mathrm{P}<0.05)$, which indicated left ventricular systolic dysfunction (Table I). The ADR group proved to be a successful model of heart failure compared with the CON group, as shown in Fig. 1.

Pathological changes in the myocardium of rats with heart failure. Masson staining showed myocardial cell disarray, a small number of fractures and an increase in collagen fibres in the intercellular matrix in the heart failure model group. Furthermore, numerous vacuoles of various sizes appeared in the intercellular matrix of the subendocardial myocardium and subepicardial myocardium, and a small number of vacuoles 

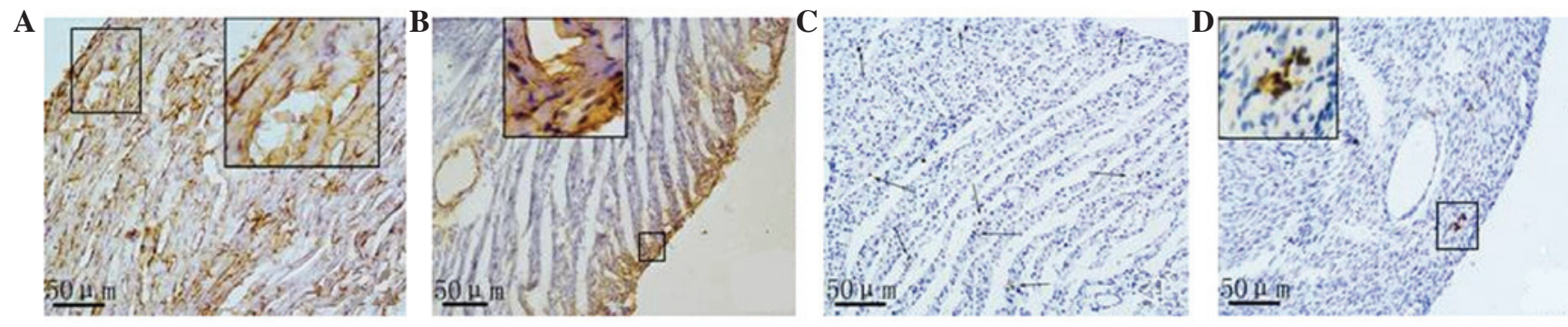

Figure 3. Expression of (A and B) nanog and (C and D) c-kit in the myocardial tissue samples of normal control rats and rats with heart failure as determined by immunohistochemical staining. Magnification, x400. Images are magnifications of positive regions. Arrows indicate positive expression cells which were scattered or in clusters.
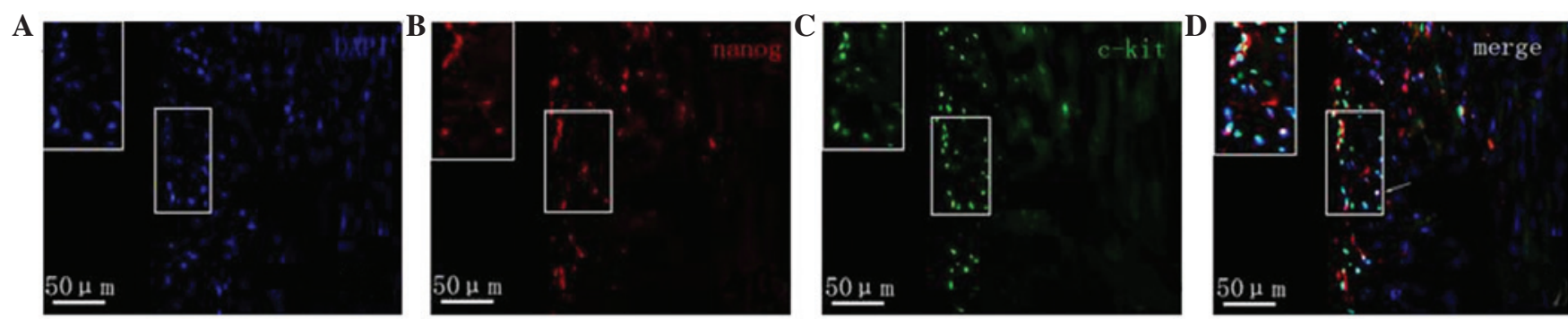

Figure 4. (A) Staining with DAPI and immunofluorescence staining of (B) nanog and (C) c-kit in the myocardial tissue samples of normal control rats. (D) Merged images of the stains. Magnification, x400. Images are magnifications of positive regions. Arrows indicate positive expression cells which were scattered or in clusters.
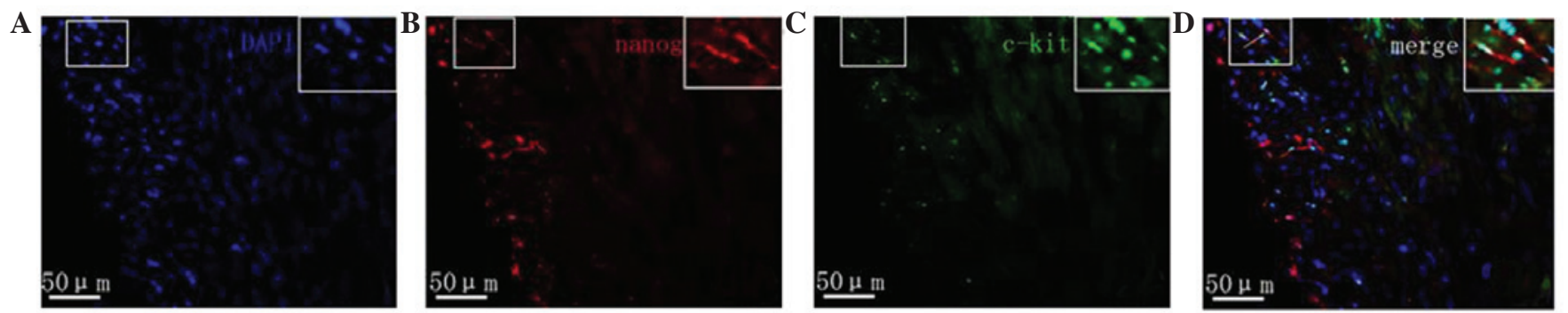

Figure 5. (A) Staining with DAPI and immunofluorescence staining of (B) nanog and (C) c-kit in the myocardial tissue samples of rats with heart failure. (D) Merged images of the stains. Magnification, x400. Images are magnifications of positive regions. Arrows indicate positive expression cells which were scattered or in clusters.

were similar with lumen sections (Fig. 2). Conversely, normal myocardial cells exhibited less interstitial collagen fibres and almost no vacuolation in the subendocardial myocardium and subepicardial myocardium (Fig. 2).

Immunohistochemical analysis of the protein expression of c-kit and nanog. Based on the results of the immunohistochemical analysis, a small amount of nanog and c-kit proteins were expressed in the rat myocardial tissue samples both in the CON and ADR groups. Nanog expression in the normal myocardial tissue samples was lower compared with that in the cardiomyocytes and vascular endothelial cells in the control group. A smaller amount of nanog expression in normal myocardial tissue existed in cardiomyocytes, endothelial cells and stem cells. Myocardial cells with positive nanog expression were scattered or in clusters was observed in the CON group. Nanog was expressed in the majority of the vascular endothelial cells. Nanog-positive stem cells were often single or in clusters, and they were located between myocytes or around the small blood vessels. In the myocardial tissue samples of the rats with heart failure, three types of nanog-positive cells (cardiomyocytes, endothelial cells, small and round stem cells) decreased, and the subendocardial myocardium and subepicardial myocardium presented a positive distribution (Fig. 3).

In the myocardial tissue samples of both rats with normal hearts and those with heart failure, c-kit-positive cells were expressed predominantly in the small round or oval cells that were present in small clusters. No positive c-kit expression was observed in cardiomyocytes or endothelial cells. Compared with the normal myocardium, the number of c-kit-positive cells was markedly reduced in the myocardium of rats with heart failure.

Protein expression of c-kit and nanog as determined by immunofluorescence. Fluorescence microscopy revealed that in the myocardial tissue samples of the normal group nanog protein expression was increased, specifically in the cardiomyocytes, vascular endothelium and small round cells. Cells with strong positive expression were unevenly distributed. Nanog-positive 
cells in the myocardial tissue samples of rats with heart failure were predominantly distributed in the subendocardial myocardium and subepicardial myocardium. The expression of nanog in the subendocardial myocardium and subepicardial myocardium was markedly lower compared with that of the normal myocardium, and its expression in the subendocardial myocardium was downregulated compared with that in the subepicardial myocardium (Fig. 4). The c-kit protein was predominantly expressed in small cells, which were often in clusters distributed in the myocardium rather than evenly distributed. c-kit-positive cells were predominantly located in the myocardium of the subepicardial myocardium. Compared with normal myocardial tissue, the number of c-kit-positive cells in the rats with heart failure was markedly reduced. c-kit fluorescence was not observed in cardiomyocytes and endothelial cells. Furthermore, a small number of cells co-expressed both the c-kit and nanog genes (Fig. 5).

\section{Discussion}

Heart failure, which has high incidence, morbidity and mortality rates, is the final stage of the majority of cardiovascular diseases $(14,15)$. Therefore, the treatment of chronic heart failure remains a severe challenge faced by medical workers. In recent years, a growing number of studies have demonstrated that cell proliferation exists in myocardial tissues, and that cardiac stem cells capable of differentiation are also isolated from myocardial tissues $(16,17)$. These stem cells have the ability to differentiate both in vitro and in vivo into cardiomyocytes, providing a possible therapeutic strategy for heart failure treatment. Ishikawa et al (18) reported the mitosis phenomenon of cardiac myocytes in normal adult rats was found, and c-kit was one of the heart surface markers, and can be found in embryonic, neonatal and adult mammalian hearts. The study (18) also demonstrated that the number of c-kit may reflect the developmental or physiological stage of such settlement cells (normal cells which exist in certain parts of the bodies) (19). Recently, c-kit-positive cells have been used in clinical trials for the preliminary treatment of heart diseases (20), including myocardial regeneration originated from coronary heart ball cell following myocardial infarction (21), and functional analysis of cardiac stem cells in ischemic myocardium (22). These stem cells have been used for the preliminary treatment of heart diseases. In 2003, Chambers et al (23) and Mitsui et al (24) reported that the nanog gene, which is predominantly expressed in undifferentiated embryonic stem cells, partial adult cells and tumor cells, facilitates embryonic stem cell self-renewal, maintains its undifferentiated state and promotes its proliferation (25). Furthermore, the nanog gene may also be used for regulating and promoting myocardial cells from re-entering the division cycle (26).

The results of the present study demonstrated that the number of c-kit- and nanog-positive cells was reduced in rats with heart failure, the corresponding proteins and mRNA levels of positive c-kit and nanog in myocardial tissue samples in normal adult rats and rats with heart failure were also decreased. The results of the present study also demonstrated that c-kit and nanog were correlated with the degree of ventricular remodelling, which demonstrated that neutrophils are able to secrete a large number of inflammatory cells (27), and inhibit the expression of c-kit and nanog during early inflammation $(28,29)$. In the present study, this pathological process was verified from the molecular and genetic level. These results were concordant with those of Senyo et al (22), who reported that the annual renewal rate of the aforementioned stem cells in adult hearts is $4-10 \%$, whereas the inhibition, while the inhibition of c-kit and nanog expression levels could decrease this renewal rate. Therefore, cardiac stem cells with c-kit and nanog surface markers are important for cardiac self-renewal and self-repair $(30,31)$.

The immunofluorescence analysis demonstrated that a small number of cells co-expressed c-kit and nanog, results which were concordant with those of our previous studies $(32,33)$. Heart failure not only severely damages the heart muscle cells, it also reduces the number of c-kit-positive cells, nanog-positive cells and stem cells $(34,35)$. These results may be observed for the following reasons: i) Environmental changes in the myocardium following heart failure can result in conditions that are no longer suitable for stem cell growth and proliferation in rats; ii) cell apoptosis may occur following heart failure; iii) ADR may be toxic for the modelling of cardiac stem cells (36). Regardless of these factors, the reduction of both cardiac stem cells and associated substances that promote the formation, development and transformation of stem cells, are not conducive to myocardial injury repair. However, whether the small number of cells with the two genetic materials (c-kit and nanog) reflects the diversity of stem cell function or represents two different cardiac stem cells requires further investigation.

\section{References}

1. Khan R and Ly HQ: Transradial percutaneous coronary interventions in acute coronary syndrome. Am J Cardiol 114: 160-168, 2014.

2. Amarenco P, Abboud H, Labreuche J, Arauz A, Bryer A, Lavados PM, Massaro A, Munoz Collazos M, Steg PG, Yamout BI and Vicaut E; OPTIC Registry Investigators: Impact of living and socioeconomic characteristics on cardiovascular risk in ischemic stroke patients. Int J Stroke 9: 1065-1072, 2014.

3. Rivera-Fernández R, Arias-Verdú MD, García-Paredes T, Delgado-Rodríguez M, Arboleda-Sánchez JA, Aguilar-Alonso E, Quesada-García G and Vera-Almazán A: Prolonged QT interval in ST-elevation myocardial infarction and mortality: New prognostic scale with QT, Killip and age. J Cardiovasc Med (Hagerstown) 17: 11-19, 2016.

4. Smith AJ, Lewis FC, Aquila I, Waring CD, Nocera A, Agosti V, Nadal-Ginard B, Torella D and Ellison GM: Isolation and characterization of resident endogenous c-Kit+ cardiac stem cells from the adult mouse and rat heart. Nat Protoc 9: 1662-1681, 2014.

5. Di Stefano R, Felice F, Pini S, Mazzotta G, Bovenzi FM, Bertoli D, Abelli M, Borelli L, Cardini A, Lari L, et al: Impact of depression on circulating endothelial progenitor cells in patients with acute coronary syndromes: A pilot study. J Cardiovasc Med (Hagerstown) 15: 353-359, 2014.

6. Wöhrle J, von Scheidt F, Schauwecker P, Wiesneth M, Markovic S, Schrezenmeier H, Hombach V, Rottbauer W and Bernhardt P: Impact of cell number and microvascular obstruction in patients with bone-marrow derived cell therapy: Final results from the randomized, double-blind, placebo controlled intracoronary Stem Cell therapy in patients with Acute Myocardial Infarction (SCAMI) trial. Clin Res Cardiol 102: 765-770, 2013.

7. Luo H, Li Q, Pramanik J, Luo J and Guo Z: Nanog expression in heart tissues induced by acute myocardial infarction. Histol Histopathol 29: 1287-1293, 2014.

8. Carvalho JL, Braga VB, Melo MB, Campos AC, Oliveira MS, Gomes DA, Ferreira AJ, Santos RA and Goes AM: Priming mesenchymal stem cells boosts stem cell therapy to treat myocardial infarction. J Cell Mol Med 17: 617-625, 2013. 
9. Rahbarghazi R, Nassiri SM, Ahmadi SH, Mohammadi E, Rabbani S, Araghi A and Hosseinkhani H: Dynamic induction of pro-angiogenic milieu after transplantation of marrow-derived mesenchymal stem cells in experimental myocardial infarction. Int J Cardiol 173: 453-466, 2014.

10. Malick M, Gilbert K, Barry M, Godbout R and Rousseau G: Desvenlafaxine reduces apoptosis in amygdala after myocardial infarction. Brain Res Bull 109: 158-163, 2014.

11. Naaijkens BA, van Dijk A, Meinster E, Kramer K, Kamp O, Krijnen PA, Niessen HW and Juffermans LJ: Wistar rats from different suppliers have a different response in an acute myocardial infarction model. Res Vet Sci 96: 377-379, 2014.

12. Chong JJ, Chandrakanthan V, Xaymardan M, Asli NS, Li J, Ahmed I, Heffernan C, Menon MK, Scarlett CJ, Rashidianfar A, et al: Adult cardiac-resident MSC-like stem cells with aproepicardial origin. Cell Stem Cell 9: 527-540, 2011.

13. Reuther S, Reiter M, Raabe A and Dikomey E: Effect of irradiation on the expression of DNA repair genes studied in human fibroblasts by real-time qPCR using three methods of reference gene validation. Radiat Environ Biophys 52: 463-469, 2013.

14. Anders B, Alonso A, Artemis D, Schäfer A, Ebert A, Kablau M, Fluechter S, Findeisen P, Hennerici MG and Fatar M: What does elevated high-sensitive troponin I in stroke patients mean: Concomitant acute myocardial infarction or a marker for high-risk patients? Cerebrovasc Dis 36: 211-217, 2013.

15. Regnault V, Lagrange J, Pizard A, Safar ME, Fay R, Pitt B, Challande P, Rossignol P, Zannad F and Lacolley P: Opposite predictive value of pulse pressure and aortic pulse wave velocity on heart failure with reduced left ventricular ejection fraction: Insights from an Eplerenone Post-Acute Myocardial Infarction Heart Failure Efficacy and Survival Study (EPHESUS) substudy. Hypertension 63: 105-111, 2014.

16. Crafts TD, Jensen AR, Blocher-Smith EC and Markel TA: Vascular endothelial growth factor: Therapeutic possibilities and challenges for the treatment of ischemia. Cytokine 71: 385-393, 2015.

17. Przybyt E, Krenning G, Brinker MG and Harmsen MC: Adipose stromal cells primed with hypoxia and inflammation enhance cardiomyocyte proliferation rate in vitro through STAT3 and Erk1/2. J Transl Med 11: 39, 2013.

18. Ishikawa K, Fish K, Aguero J, Yaniz-Galende E, Jeong D, Kho C, Tilemann L, Fish L, Liang L and Eltoukhy AA: Stem cell factor gene transfer improves cardiac function after myocardial infarction in swine. Circ Heart Fail 8: 167-174, 2015.

19. Malliaras K, Makkar RR, Smith RR, Cheng K, Wu E, Bonow RO, Marbán L, Mendizabal A, Cingolani E, Johnston PV, et al: Intracoronary cardiosphere-derived cells after myocardial infarction: Evidence of therapeutic regeneration in the final 1-year results of the CADUCEUS trial (Cardiosphere-Derived autologous stem Cells to reverse ventricular dysfunction). J Am Coll Cardiol 63: 110-122, 2014

20. Galiger C, Kostin S, Golec A, Ahlbrecht K, Becker S, Gherghiceanu M, Popescu LM, Morty RE, Seeger W and Voswinckel R: Phenotypical and ultrastructural features of Oct4-positive cells in the adult mouse lung. J Cell Mol Med 18: 1321-1333, 2014

21. Mendjan S, Mascetti VL, Ortmann D, Ortiz M, Karjosukarso DW, $\mathrm{Ng}$ Y, Moreau T and Pedersen RA: NANOG and CDX2 pattern distinct subtypes of human mesoderm during exit from pluripotency. Cell Stem Cell 15: 310-325, 2014.

22. Senyo SE, Steinhauser ML, Pizzimenti CL, Yang VK, Cai L, Wang M, Wu TD, Guerquin-Kern JL, Lechene CP and Lee RT: Mammalian heart renewal by pre-existing cardiomyocytes. Nature 493: 433-436, 2013.
23. Chambers I, Colby D, Robertson M, Nichols J, Lee S, Tweedie S and Smith A: Functional expression cloning of Nanog, a pluripotency sustaining factor in embryonic stem cells. Cell 113: 643-655, 2003.

24. Mitsui K, Masamune T, Okuyama K, Oguchi T, Furuya A, Iwashita $\mathrm{H}$, Ishiyama $\mathrm{T}$ and Matsukawa $\mathrm{T}$ : [A case of severe hypotension caused by external cardiac compression by tumor and doctor's hand in a patient with mediastinal tumor]. Masui 62: 204-208, 2013.

25. Lahm H, Doppler S, Dreßen M, Werner A, Adamczyk K, Schrambke D, Brade T, Laugwitz KL, Deutsch MA, Schiemann M, et al: Live fluorescent RNA-based detection of pluripotency gene expression in embryonic and induced pluripotent stem cells of different species. Stem Cells 33: 392-402, 2015

26. Kajstura J, Rota M, Cappetta D, Ogórek B, Arranto C, Bai Y, Ferreira-Martins J, Signore S, Sanada F, Matsuda A, et al: Cardiomyogenesis in the aging and failing human heart. Circulation 126: 1869-1881, 2012 .

27. Cieslik KA, Trial J, Crawford JR, Taffet GE and Entman ML: Adverse fibrosis in the aging heart depends on signaling between myeloid and mesenchymal cellRole of inflammatory fibroblasts. J Mol Cell Cardiol 70: 56-63, 2014.

28. Duran JM, Makarewich CA, Sharp TE, Starosta T, Zhu F, Hoffman NE, Chiba Y, Madesh M, Berretta RM, Kubo H, et al: Bone-derived stem cells repair the heart after myocardial infarction through transdifferentiation and paracrine signaling mechanisms. Circ Res 113: 539-552, 2013

29. Wehman B, Sharma S, Mishra R, Guo Y, Colletti EJ, Kon ZN, Datla SR, Siddiqui OT, Balachandran K and Kaushal S: Pediatric End-Stage Failing Hearts Demonstrate Increased Cardiac Stem Cells. Ann Thorac Surg 100: 615-622, 2015.

30. Hariharan N, Quijada P, Mohsin S, Joyo A, Samse K, Monsanto M, De La Torre A, Avitabile D, Ormachea L, McGregor MJ, et al: Nucleostemin rejuvenates cardiac progenitor cells and antagonizes myocardial aging. J Am Coll Cardiol 65: 133-147, 2015.

31. Chugh AR, Beache GM, Loughran JH, Mewton N, Elmore JB, Kajstura J, Pappas P, Tatooles A, Stoddard MF, Lima JA, et al: Administration of cardiac stem cells in patients with ischemic cardiomyopathy: The SCIPIO trial: Surgical aspects and interim analysis of myocardial function and viability by magnetic resonance. Circulation 126 (11 Suppl 1): S54-S64, 2012.

32. Ellison GM, Galuppo V, Vicinanza C, Aquila I, Waring CD, Leone A, Indolfi C and Torella D: Cardiac stem and progenitor cell identification: Different markers for the same cell? Front Biosci (Schol Ed) 2: 641-652, 2010.

33. Xue C, Zhang J, Lv Z, Liu H, Huang C, Yang J and Wang T: Angiotensin II promotes differentiation of mouse c-kit-positive cardiac stem cells into pacemaker-like cells. Mol Med Rep 11: 3249-3258, 2015.

34. Fortini C, Cesselli D, Beltrami AP, Bergamin N, Caragnano A, Moretti L, Cecaro F, Aquila G, Rizzo P, Riberti C, et al: Alteration of Notch signaling and functionality of adipose tissue derived mesenchymal stem cells in heart failure. Int J Cardiol 174: 119-126, 2014.

35. Igura K, Okada M, Kim HW and Ashraf M: Identification of small juvenile stem cells in aged bone marrow and their therapeutic potential for repair of the ischemic heart. Am J Physiol Heart Circ Physiol 305: H1354-H1362, 2013.

36. Jasmin, Jelicks LA, Tanowitz HB, Peters VM, Mendez-Otero R, Campos de Carvalho AC and Spray DC: Molecular imaging, biodistribution and efficacy of mesenchymal bone marrow cell therapy in a mouse model of Chagas disease. Microbes Infect 16: 923-935, 2014. 